\title{
Bioassay study on treated effluent of basic drug industries of Mandideep industrial area of Madhya Pradesh, India
}

\begin{abstract}
Effluent from basic drug industries may have unknown toxicity, teratogenicity, carcinogenicity profile associated with lack of monitoring and control measures impose a significant hazard risk on the public health and biological environment. Therefore, toxicity study of the treated effluent from effluent treatment plant of basic drug industries is important. Mandideep industrial area near Bhopal city of Madhya Pradesh, that large number of suppliers of bulk drugs to the international market as well as to local market. For the study purpose, total two basic drug industries were selected in Madideep industrial area for bioassay test by Poecilia libestes reticulate (Guppy fish). Monitoring of basic drug industrial effluents was performed as per guidelines of Central Pollution Control Board and bioassay test was performed as per BIS: 6582 (1971) method. This study concluded by graphical values of $90 \%$ survival of tested fishes at $50 \%$ dilution in $96 \mathrm{hrs}$, that represented as lethal concentration 50 (LC50). The observation reveals that $6 \%$ LC50 of effluent from ETP II Lupin Ltd during II quarter (July to September), 85\% LC50 of effluent from ETP I Lupin Ltd during III quarter (October to December), $11.23 \%$ LC50 of effluent from ETP II Lupin Ltd during III quarter (October to December), 5\% of LC50 of raw effluent from Vista Organics (P) Ltd during III quarter (October to December) and 42.5\% LC50 of mixed effluent from ETP I \& ETP II Lupin Ltd during IV quarter (January to March) were found acute toxic during this study. Treated effluent from both industries was found free from acute lethal toxicity w.r.t. Bio assay test.
\end{abstract}

Keywords: basic drug industry, effluent treatment plant, treated effluent, bioassay test, $\mathrm{LC}_{50}$
Volume 3 Issue 5 - 2019

Reeta Kori,Alok Saxena, Sandhya Mokhle, Vineeta Goutam, Ankita Kulshreshtha, Vandana Ramnani, Makhan Parmar

Central Laboratory, Madhya Pradesh Pollution Control Board, India

Correspondence: Ankita Kulshreshtha, Central Laboratory, Madhya Pradesh Pollution Control Board, Paryavaran Parisar, E-5,Arera Colony, Bhopal, Madhya Pradesh, India, Email ankita.kuls@gmail.com

Received: July 16, 2019 | Published: October 01, 2019
Abbreviations: COD, chemical oxygen demand; BOD, biochemical oxygen demand; SS, suspended solids; TDS, total dissolved solids; LC, lethal concentration

\section{Introduction}

Effluent from basic drug manufacturing industries originates from cleaning activities after batch operation during the synthesis process. They may contain toxic organics, residues which pose a threat to the quality of surface and groundwater. Effluent therefore contains all the unconverted raw materials, the intermediate products in different stages and finally form a cocktail mixture of these compounds dissolved in the solvents. The effluent also contains variety of trace metals that happens to have entered due to the reaction of effluent with storage containers and metal pipes and fittings. Apart from the above substances gel, oil and grease is also generated. ${ }^{1}$ As basic drugs industrial waste effluents are highly variable in composition depending on plant production schedules and are composed principally of soluble organic substances which cannot be removed by precipitation or adsorption on to biological flocs or may contain exotic chemical species which would interfere with conventional treatment processes when treating waste of this type. Biological process would be most effective in removing short chained and other degradable organic constituents while physical and chemical process such as adsorption, using activated carbon would be required to remove substances refractory to biological treatment. The secondary treatment in most of the cases may not be necessary and if needed, stabilization ponds may be recommended.

A variety of types of organisms representing different trophic le- vels and many different species are used for aquatic toxicity testing. Toxicity characterization would be needed both for influents and effluents of effluent treatment plant. For the purpose of screening biological effluent treatment influent, toxicity to activated sludge microorganisms is important and toxicology tests here used are respirometry and bioluminescence toxicology tests. Bioassay (commonly used shorthand for biological assay or assessment) or biological standardization is a type of scientific experiment. A bioassay involves the use of live animal or plant (in vivo) or tissue or cell (in vitro) to determine the biological activity of a substance, such as a hormone or drug. Bioassays are typically conducted to measure the effects of a substance on a living organism and are essential in the development of new drugs and in monitoring environmental pollutants. Both are procedures by which the potency or the nature of a substance is estimated by studying its effects on living matter. A bioassay can also be used to determine the concentration of a particular constitution of a mixture that may cause harmful effects on organisms or the environment. Environmental bioassays are generally a broad-range survey of toxicity. A toxicity identification evaluation is conducted to determine what the relevant toxicants are. Although bioassays are beneficial in determining the biological activity within an organism, they can often be time-consuming and laborious. "Bioassay signifies a test in which a living tissue, organism or a group of organisms is used as test material for the determination of the potency of any physiologically active substance of unknown activity". A complete evaluation of effluents should include eco toxicological tests too, especially concerning the complex effluents. Therefore risks that are associated with environmental discharge from pharmaceutical manufacturing differ in several 
respects from those that are associated with the excretion of drugs may be hazardous. Industrial effluent may disturbed the aquatic life when it discharged in to the natural water. Fish are the primary bio indicator as they are very sensitive towards the pollution. Therefore objective of this study is to know about toxicity level with special reference to Bioassay test of effluent discharge by basic drug industries around Mandideep area. Bulk drug or pharmaceutical units usually involve complex manufacturing processes that consume large quantity of organic or inorganic materials and generate wastewater, which is never consistent in characteristics. These wastewaters normally consist of solids in dissolved form and substances that are toxic and refractory natured. ${ }^{2}$ These refractory organics either due to their complex chemical structure or due to their toxic nature are resistant to biodegradation. Organic, inorganic and toxic substances present in the bulk drug effluents have direct impact on the aquatic life and hence have high ecological relevance. It is very difficult to relate observed effects to specific pollutants present in the industrial effluents, which remains a confused field due to the presence of unknown complex and often-fluctuating characteristics of the effluent. Effluent has high Chemical Oxygen Demand (COD), Biochemical Oxygen Demand (BOD), Suspended Solids (SS) and Total Dissolved Solids (TDS) and cannot be discharged without proper treatment. Basic drug industrial effluents apart from being hazardous to public health have been also found to cause serious damage to the fauna.

The fishes have been considered as useful index for the purity of water and no river should be considered in a satisfactory condition unless fishes thrive well in it. ${ }^{3}$ Bioassay studies for effluents from wastewater treatment plants provides a complete response of test organisms to compounds present in wastewater and to understand the discharge capacity of the raw and treated wastewaters. ${ }^{4-6}$ In recent years more attention is being given to acute toxicity evaluation for industrial effluents due to the imposition of stringent laws on discharge standards. ${ }^{7}$ Chemical industries/chemical based pharmaceutical industries are the ones which generate highly toxic wastes and create acute environmental problems. ${ }^{8}$ A detailed literature survey regarding the fate and mobility of several pharmaceutical compounds on different aquatic species is reported. ${ }^{9}$ Toxicity evaluation of spent broth from an antibiotic unit on Lebiscus recticulatus has been cited in the literature. ${ }^{10}$ Several studies on electrochemical treatment of industrial wastes have been reported towards destruction/detoxification of organics, while none of the studies towards toxicity evaluation on electrochemically treated wastewaters has been reported so far. Bioassay studies were carried by choosing the locally available fresh water fish, which is widely found in natural water bodies in India. ${ }^{11}$ Pollution of waste bodies affects all the biotic communities, including fish. Main sources of water pollution are domestic waste, industrial waste, effluent, pesticides, fertilizers and thermal pollution. Industrial effluents adversely affect our spot and commercial fisheries, because such effluents generally have high temperatures, very low DO, high BOD, many type of toxic substances, including pesticides other toxic chemicals and heavy metals. Many industrial effluents are extremely complex in nature, containing thousands of different compounds. The effects of water pollution on fisheries are so varied and extensive that until detailed analysis of the water is done for all harmful ingredients, it is quiet difficult to pin point the causes of toxicity and mass mortality. In the existing analytical procedures, to evaluate the toxicity of waste water or effluents we assess the certain parameters such as heavy metal, pesticides or other organic compounds. But still we cannot say how toxic a particular sample is, as no instrumental analysis is available to estimate the toxicity of pure chemical or complex waste to living organisms. To cope up this issue, toxicity test can be a boon in water quality analysis wherein assessment of and degree of pollution is calculated. It is therefore urgently required to assess the toxicity of effluent.

\section{Methodology}

\section{Study area}

Mandideep is a municipality in Goharganj subdistrict of Raisen district in the Indian state of Madhya Pradesh. It is situated between the latitude $22^{\circ} 47^{\prime} \& 23^{\circ} 33^{\prime}$ north and the longitude $77^{\circ} 21^{\prime} \& 78^{\circ} 49^{\prime}$ east and is bounded in the west by Sehore District, in the north by Vidisha District, in the east, southeast by Sagar District, and in the south by Hoshangabad and Sehore districts. ${ }^{12}$ Total two basic drug pharmaceutical units of Mandideep industrial area were selected for this study, namely

\section{M/s Lupin limited, Mandideep}

Lupin Limited is a transnational pharmaceutical company based in Mumbai. It is the seventh-largest company by market capitalization; and the 10th-largest generic pharmaceutical company by revenue globally. Lupin Limited, Mandideep has two effluent treatment plants (ETP- I and ETP -II) followed by the recycling facility: RO, MEE and ATFD plants, to recover water for recycling and reuse. ETP -I is low polluted sources with capacity of $100 \mathrm{KL} / \mathrm{D}$ and ETP-II is High polluted sources with capacity of $600 \mathrm{KL} / \mathrm{D}$. The additional effluent generated shall be treated in the ETP II and will further get processed in the recycling facility. Lupin Limited, Mandideep has this expansion of ETP II and the recycling facility to maintain "Zero Liquid Discharge" conditions at the site. Effluent generated from the formulation units are identified as low COD streams and they are treated in Effluent Treatment Plant I. The effluent from the bulk manufacturing units has been identified as high COD streams and they are treated in Effluent Treatment Plant II. The treated effluent is then processed through Reverse Osmosis units. ${ }^{13}$

\section{M/s Vista organics (P) limited, Mandideep}

Vista Organics (P) Ltd, is one of the major producers of Pyrazinamide, an anti-TB drug in India. It also manufactures INH, another anti-TB drug, Niacin, Niacinamide, Vitamin and feed supplements, Erythromycin, the well known antibiotic and Zinc picolinate for exports. Its factory is located at Mandideep, Madhya Pradesh. ${ }^{14}$ These monitoring locations are shown in Figure 1

\section{Monitoring and analysis}

Monitoring of basic drug industrial effluents was performed as per guidelines of Central Pollution Control Board on quarterly basis i.e. I quarter- April to June, II quarter-July to September, III quarterOctober to December, IV quarter-January to March and Bioassay test performed as per BIS: 6582 (1971) method. ${ }^{15}$

\section{Bioassay test}

The measure of acute toxicity is the concentration of the test sample is suitable diluents at which just 50 percent of the test animals are able to survive for a specified period of exposure. This is known as the median tolerance limit (TLm). The concentration of the sample in the diluent water is expressed as percent by volume. For example, a 10 percent concentration or a TLm of 10 percent equals 1 part of the test sample in 9 parts of the diluent water. To evaluate toxicity, different concentrations of the test sample are tested so that the concentration 
lethal to 50 percent of the test animals may be found or estimated by interpolation. Samples of effluents or waste waters which are not constant in their composition shall be controlled at different times and shall not be unnecessarily combined to make composite samples, because knowledge of the maximal toxicity of a variable effluent is often required in connection with the control of effluent disposal in flowing water rather than knowledge of the average toxicity. Extensive damage to the aquatic life of a receiving stream can result from brief, intermittent discharges of a highly toxic waste, even though the toxicity of the effluent at other times and its average toxicity are negligible. Therefore, if the composition and toxicity of an effluent vary considerably, it is necessary to test a number of individual samples taken at times when the effluent is likely to be most toxic, in order to determine the maximal toxicity. A composite sample of an effluent consisting of portions collected at regular time intervals can be useful only when average toxicity is to be evaluated. Bioassay test was performed by following test experiments with effluents.

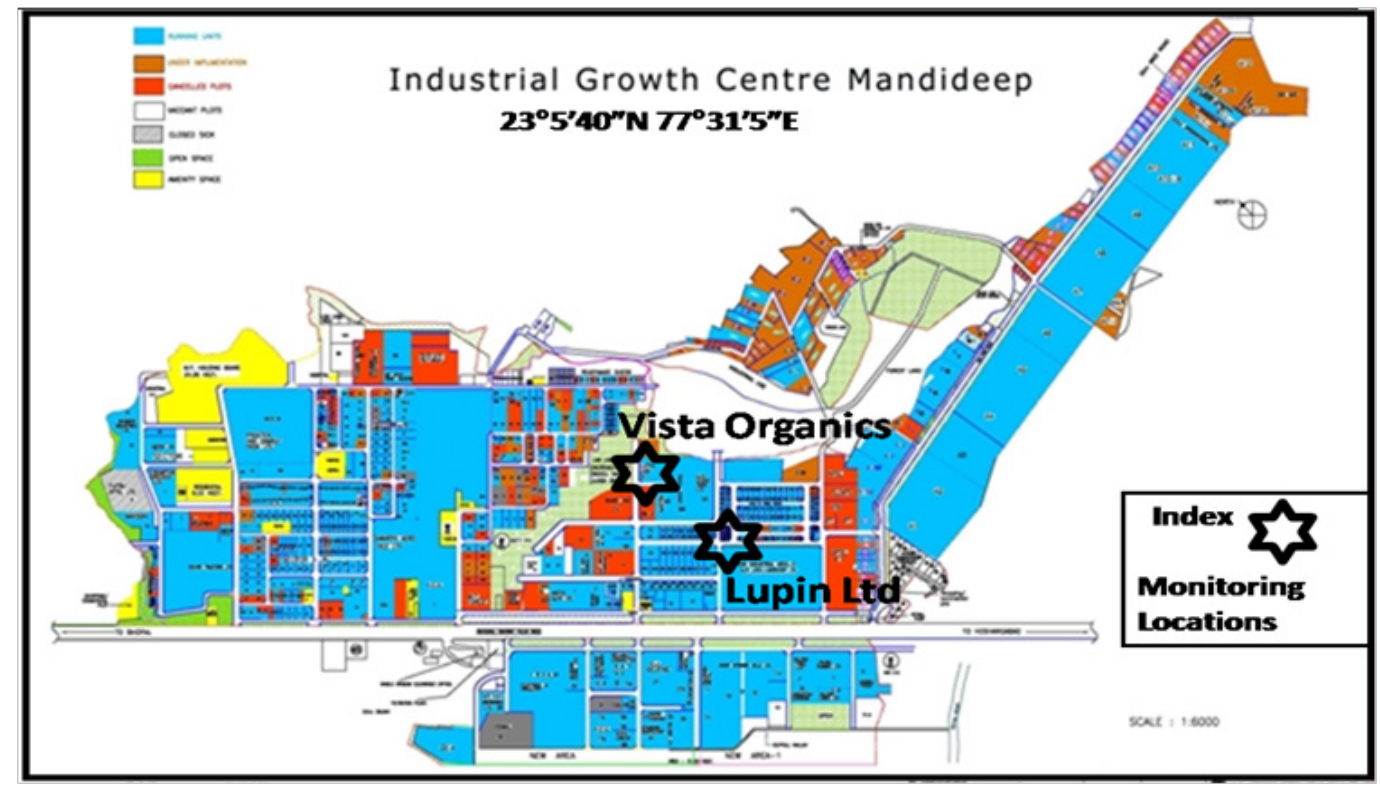

Figure I Industrial growth centre Mandideep (Monitoring locations).

\section{Preliminary test}

When testing effluents of completely unknown toxicity, much time and effort can be saved by conducting preliminary bio-assay to determine the approximate range of concentration of the effluent which should be covered in the full scale test. Prepare wide ranges of concentrations of the sample under test, for example, 100, 10, 0.1 percent with the diluents water. Place two or more test fishes in an appropriate volume of each concentration contained in wide-mouth glass bottles. Observe after 24 hours. Select for full scale test the dilution ranges between the lowest concentration at which all fish survive for 24 hours and highest concentration at which all or more fish die in 24 hours. The preliminary assay will also show whether excessive oxygen depletion occurs during the test period.

\section{Full scale bio assay}

Test at least 4 to 6 concentrations arranged at equal logarithmic intervals within the limits of dilution ascertained from the preliminary test. A concurrent control test shall also be run under exactly similar conditions using the diluent water alone. The control shall be deemed satisfactory if not more than 10 percent of the fish placed in it die within the test period. The basic Routine Bio-assay Method is widely applicable, being suitable for the detection and evaluation of acute toxicity which is not associated with excessive oxygen demand and which is due to substances that are relatively stable and are not extremely volatile. The Routine Bio-Assay method is designed so that the surface absorption of oxygen from the atmosphere plus some oxygen from the diluent generally provides an adequate amount of DO. for the fish during the test period. Many industrial effluents have a high chemical or biochemical oxygen demand, which may cause oxygen depletion in test solutions. Although it is usually necessary to use artificial supplies of air or oxygen, DO shall nevertheless be maintained at levels adequate for the test fish. ${ }^{15,16}$ The potential consequences of indirect as well as chronic (long-term) and delayed effects of the waste on the water bodies through the toxicity test were assessed by conducting $96 \mathrm{hrs}$ bioassay test. The test organism for the study will be selected according to the criteria for the selection of test organisms of United States Environmental Protection Agency. Static bioassay tests will be conducted at room temperature using fish Poecilia Libestes Reticulata (Guppy fish) as test organism. ${ }^{17,18}$

\section{Result \& discussion}

The fish may not always die but their reproductive capacity, breeding, spawning and development are adversely affected. In aquatic toxicology fish have been widely and popularly acclaimed as a test species for evaluating the potency of toxicants to cause lethacity (acute toxicity) or any other sub lethal responses, using selected behavioral biochemical or physiochemical and hematological responses. Toxicity tests have been proved extremely useful for this purpose in many parts of the world. Drug industries effluents are complex and can be polluted by non-biodegradable end toxic organic compounds and are a serious threat to the environment. Fish are affected by toxic substances chiefly in following two ways: (A) Epithelia -absorb toxic substances, getting damaged in this process, for instance, the gills stick together or get congested with mucus and get destroyed. (B) Besides the above immediate effects, harmful substances are adsorbed through the gills, skin or intestine, thereby impairing physiological functions. These effects may ultimately lead to the death of fish. ${ }^{18,19}$ The bioassay 
study results are depicted in Table 1 and $\mathrm{LC}_{50}$ concentration results are shown in Figure 2-6. The overall observations of four quarters observations of analyzed effluents from two basic drug industries are depicted in below Table 1 .

Table I Bioassay interpretation of analyzed effluents

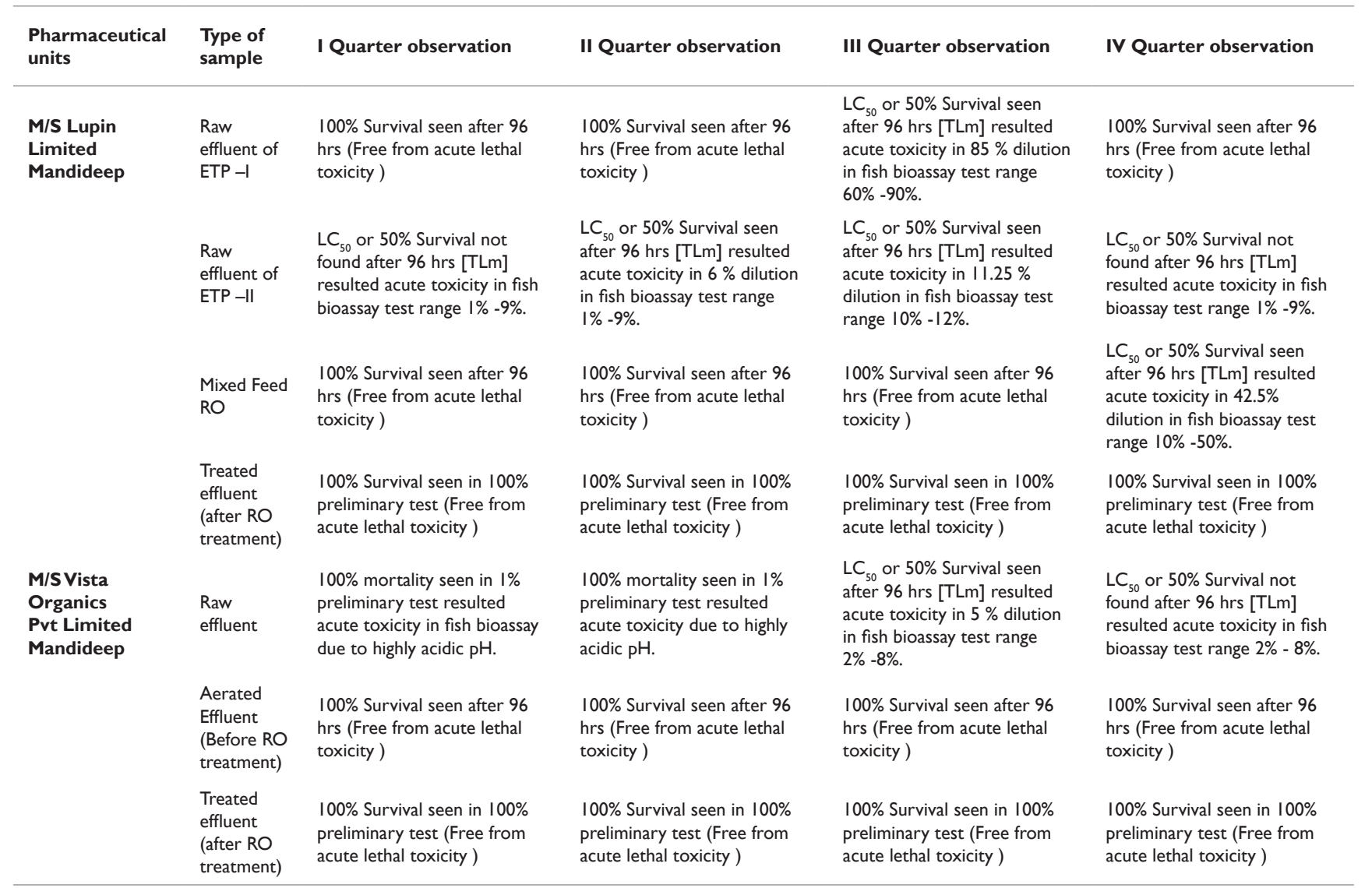

Unit -TLm , Method - BIS: $6582 \cdot 197$ I, Fish Species used for test : Guppy (Poecilia reticulate) [Fish size- I-5cm ,weight- 2-5 gm, Amb.Tem (Co) -24 Co]

In Figure $2, \mathrm{LC}_{50}$ or $50 \%$ Survival seen after $96 \mathrm{hrs}$ [TLm] resulted acute toxicity in $6 \%$ dilution in fish bioassay test range $9 \%-1 \%$ in raw effluent of ETP -II collected from Lupin ltd during II quarter.

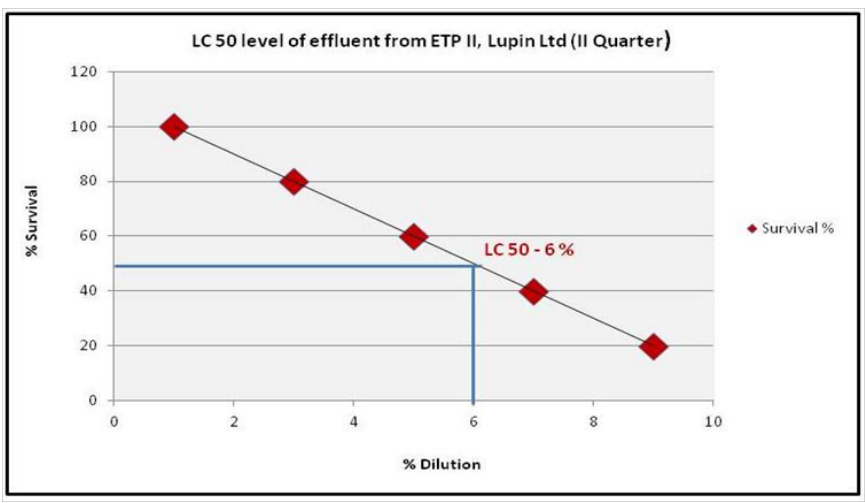

Figure 2 LC $_{50}$ level of effluent from ETP II, Lupin Ltd: II Quarter.

In Figure 3, $\mathrm{LC}_{50}$ or $50 \%$ survival seen after $96 \mathrm{hrs}$ [TLm] resulted acute toxicity in $85 \%$ dilution in fish bioassay test range $60 \%-90 \%$ in raw effluent of ETP -I collected from Lupin ltd during III quarter $100 \%$ Survival seen after $96 \mathrm{hrs}$ that represent free from acute lethal toxicity in raw effluent of ETP -I collected from Lupin ltd during I, II and IV quarter respectively.

In Figure 4, $\mathrm{LC}_{50}$ or $50 \%$ Survival seen after $96 \mathrm{hrs}[\mathrm{TLm}]$ resulted as acute toxicity in $11.25 \%$ dilution in fish bioassay test range $12 \%$ $10 \%$ in raw effluent of ETP -II collected from Lupin ltd during III quarter. $100 \%$ survival seen after $96 \mathrm{hrs}$ that represent free from acute lethal toxicity in raw effluent of ETP -II collected from Lupin ltd during I and IV quarters. The all treated effluent from Lupin Ltd was found free from acute lethal toxicity during this study.

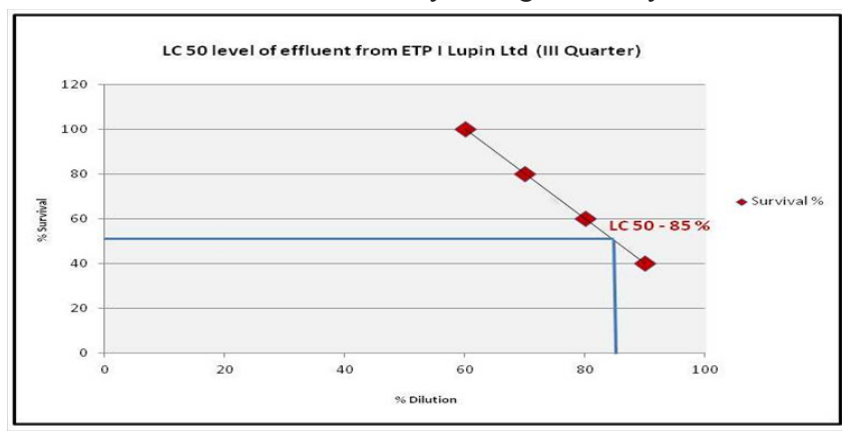

Figure 3 LC $_{50}$ level of effluent from ETP I Lupin Ltd: III Quarter. 


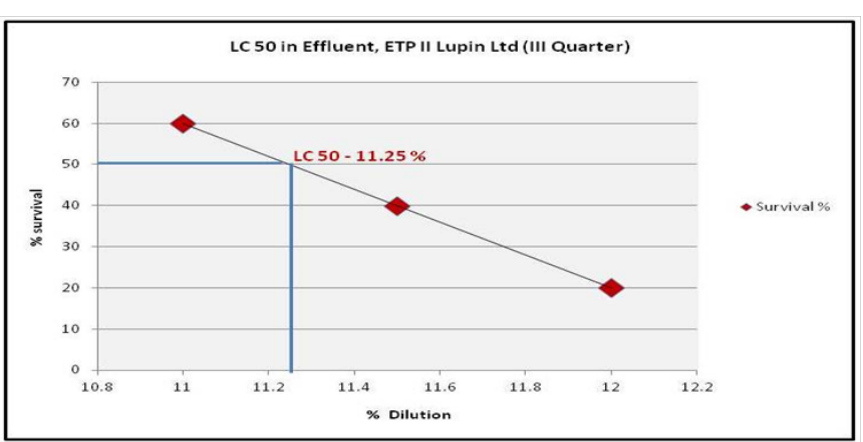

Figure 4 LC $_{50}$ level of effluent from ETP II Lupin Ltd: III Quarter.

In Figure 5, $\mathrm{LC}_{50}$ or $50 \%$ survival seen after $96 \mathrm{hrs}$ [TLm] resulted acute toxicity in 5\% dilution in fish bioassay test range $8 \%-1 \%$ in raw effluent collected from Vista organics $(\mathrm{P})$ ltd during III quarter.

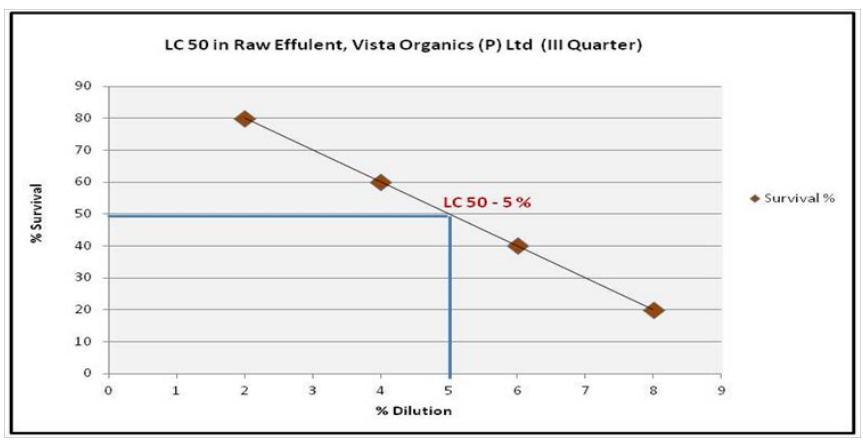

Figure 5 LC $_{50}$ level of raw effluent from Vista Organics (P) Ltd: III Quarter.

In Figure 6, $\mathrm{LC}_{50}$ or $50 \%$ Survival seen after 96hrs [TLm] results acute toxicity in $42.5 \%$ dilution in fish bioassay test range $45 \%-25 \%$ in mixed feed RO effluent collected from Vista organics (P) ltd during IV quarter. 100\% Survival seen after $96 \mathrm{hrs}$ that represent free from acute lethal toxicity in mixed feed RO effluent in I, II and III quarter and all treated effluent from Vista organics (P) ltd was found free from acute lethal toxicity during this study.

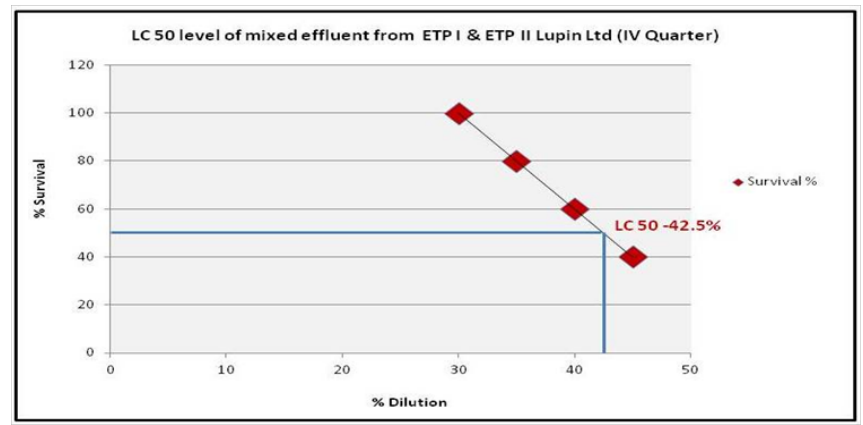

Figure 6 LC $_{50}$ level of mixed effluent from ETP I \& ETP II Lupin Ltd: IV Quarter

\section{Conclusion}

The main source of wastewater in bulk drug manufacturing industry is water release during the manufacture of medicines. The manufacturing processes involves numerous raw materials, organic and inorganic constituents including spent solvents, acid/alkalis, catalysts, reactants, intermediates and products as well in addition to the usual manufacturing streams such as pumpseal waters, waste scrubber wastewaters, boiler blow down and floor washings. The process wastewater therefore contains all these unconverted raw materials, the intermediate products in different stages and finally form a cocktail mixture of these compounds dissolved in the solvents. The wastewater also contains variety of trace metals that happens to have entered due to the reaction of wastewater with storage containers, metal pipes and fittings. This study resulted that raw effluent is toxic to the fish guppy whereas treated effluents are free form of lethal toxicity. The results provide baseline information in formulating strategy for controlled release of industrial treated effluents into the receiving water bodies. For application of toxicity data in regulation of wastewater discharges, prediction of environmental affects both acute and chronic toxic levels have to be determined to conserve aquatic life.

\section{Acknowledgments}

The all authors acknowledge the help received from authorities of basic drug industries and also thankful to the Chairman \& Member Secretary Madhya Pradesh Pollution Control Board, for encouragement of study work and kind permission to publish this paper.

\section{Conflicts of interest}

The author declares there are no conflicts of interest.

\section{References}

1. Cebere E. Faltina N. Zelcans D, et al. Toxicity Tests for Ensuring Successful Industrial Effluent Treatment Plant Operation B. Environmental and Climate Technologies. 2010;3(3):41-47.

2. Vanerkar AP, Satyanarayan S, Dharmadhikari DM. Toxicity of herbal bulk drug industry wastewater on fish- lebistes reticulatus (peter). J of Environ Sci and Health. 2004;39(1):115-123.

3. Klein SA, Jenkins D. Environmental quality research, fish and aufwuchs bioassay. 1977.

4. Shrinivas P, Banerji G, Rao P. Preliminary observations on the effect of industrial effluents to certain animals. Ind $J$ of Environ and Health. 1984;26(1):57-59.

5. Movahedian H, Bina B, Asghari GH. Toxicity evaluation of wastewater treatment plant effluents using Daphnia Magna. Iranian $J$ of Environ Health Sci \& Engg. 2005;2(2):1-4

6. Kumar S, Sahay SS, Sinha MK. Bioassay of common distillery effluent on common guppy Lebistes Recticulatus (Peter). Bull Environ Contamin \& Toxicol. 1995;54(2):309-316.

7. Maleki A, Mahvi AH, Vaezi F, et al. Ultrasonic degradation of phenol and determination of the oxidation by-products toxicity. Iranian J of Environ Health Sci \& Eng. 2005;2(3):201-206.

8. Shahtalebi A, Sarrafzadeh MH, MM Montazer Rahmati. Application of nanofiltration memberane in the separation of amoxicillin from pharmaceutical wastewater. Iranian $J$ of Environ Health Sci \& Engg. 2011;8(2):109-116.

9. Enick OV, Moore MM. Assessing the assessments: Pharmaceuticals in the environment. Environ Imp Assess Rev. 2007;27(8):707-729.

10. Satyanarayan S, Kotangale JP, Satyanarayan A, et al. Toxicity of spent broth from an antibiotic unit to fish-lebistes reticulatus (peter). Poll Res. 2005;24(2):439-442.

11. Bazrafshan E, Mahvi AH, Nasseri S, et al. Performance evaluation of electrocoagulation process for diazinon removal from aqueous environments by using iron electrodes. Iran J of Environ Health Sci \& Eng. 2007;4(2):127-132.

12. https://en.wikipedia.org/wiki/Mandideep. 
13. http://www.mppcb.nic.in/pdf/590lupinenglish.pdf

14. https://economictimes.indiatimes.com/resonance

15. Bio-assay methods for evaluating acute toxicity of industrial effluents and wastewaters. 2001.

16. Ecological Effects Test Guidelines OPPTS 850.1075. Fish Acute Toxicity Test, Freshwater and Marine. EPA 712-C-96-118. 1996.
17. Doudoroff P, Anderson BG, Burdick GE, et al. Bioassay methods for the evaluation of acute toxicity of industrial wastes to fish. Sewage \& Ind Wastes. 1951;23(11):130-136.

18. Standard Methods for examination of water and effluent. $23^{\text {rd }}$ edn. Washington: American Public Health Association. 2017.

19. Sprague JB. Measurement of pollutant toxicity to fish 1-Bioassay methods for acute toxicity. Water Res. 1969;3(11):793-796. 